\title{
O LUGAR DA ARGUMENTAÇÃO NA ANÁLISE DO DISCURSO: ABORDAGENS E DESAFIOS CONTEMPORÂNEOS
}

RESUMO: Com orientação ou simplesmente dimensão argumentativa, a argumentação será sempre parte integrante do discurso em situação. Ela deve por isso ser levada em conta pela $\mathrm{AD}$, a quem compete tanto explorar sua inscrição na materialidade linguageira quanto sua ancoragem social e institucional. A abordagem aqui proposta é exemplificada por intermédio da análise de uma carta de Alfred Dreyfus. Retomando a Retórica Antiga, a qual submete aos desenvolvimentos das ciências da linguagem, a argumentação no discurso opõe-se à argumentação na língua que nega as virtudes do logos. Frente às posições que a este negam formalmente qualquer poder, faz-se importante ressaltar o compartilhamento da fala que está na base tanto das relações humanas como da responsabilidade cidadã.

PALAVRAS-CHAVE: Análise do discurso; argumentação; finalidade e dimensão argumentativas; argumentação linguiística vs retórica; logos; situação de discurso.

INTRODUÇÃO

A argumentação é inerente ao funcionamento do discurso

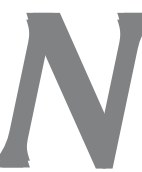

a medida em que a análise do discurso (AD) entende descrever o funcionamento do discurso em situação, ela não pode evitar sua dimensão argumentativa. Sem dúvida, o ato de tomar a palavra nem sempre se destina a conduzir o público a aprovar uma tese. ${ }^{1}$ Da conversa cotidiana aos textos

Universidade de Tel-Aviv, Israel. Tradução de Adriana Zavaglia.

1 Definição de argumentação proposta pela nova retórica de C. Perelman e L. OlbrechtsTyteca (1958). 
literários, muitos são os discursos que não têm orientação argumentativa. Entretanto, a fala que não tem a intenção de convencer acaba por exercer alguma influência, orientando maneiras de ver e de pensar. De fato, "o exercício da fala implica normalmente vários participantes - os quais exercem permanentemente uns sobre os outros uma rede de influências mútuas: falar é trocar, e é mudar trocando" $^{2}$ (Kerbrat-Orecchioni, 1990, p. 54-5).

Nos termos de Charaudeau, todo ato de linguagem emana de um sujeito que gera sua relação com o outro (princípio de alteridade) de maneira a influenciá-lo (princípio de influência) e, ao mesmo tempo, a gerar uma relação na qual o interlocutor tem seu próprio projeto de influência (princípio de regulação) (Charaudeau, 2005, p. 12). Percebe-se, portanto, que, por sua natureza dialógica, o discurso comporta como qualidade intrínseca a capacidade de agir sobre o outro, de influenciá-lo. Sem dúvida, é preciso manter a distinção entre a estratégia de persuasão programada e a tendência de todo discurso de orientar as maneiras de ver do(s) interlocutor(es). No primeiro caso, o discurso manifesta uma orientação argumentativa: o discurso eleitoral ou a publicidade constituem exemplos flagrantes disso. No segundo caso, ele comporta simplesmente uma dimensão argumentativa (Amossy, 2006 [2000], 2005): assim acontece com o artigo informativo que preza por sua neutralidade, a conversa coloquial ou o texto ficcional. Mas a argumentação, apresente ela ou não uma vontade manifesta de conduzir à aprovação, é sempre parte integrante do discurso em situação. Compete também ao analista descrever suas modalidades da mesma maneira que outros processos linguageiros.

De todo modo, tal é a posição que eu gostaria de defender aqui ao articular a argumentação (ou a retórica concebida como a

N.T.: Há, nessa citação, um rico jogo de palavras em francês, sobre échanger (trocar) e changer (mudar, trocar) que vale a pena transcrever: parler, c'est échanger, et c'est changer en échangeant. 
arte de persuadir $)^{3}$ à $\mathrm{AD}$ da forma como é hoje praticada na França na esteira dos trabalhos de Patrick Charaudeau e Dominique Maingueneau. Este texto tratará, portanto, não somente do estudo do "uso real da linguagem por locutores reais em situações reais" (definição já conhecida de Teun van Dijk em seu Handbook of Discourse Analysis, 1985, p. 2), mas também da abordagem que relaciona a fala a um lugar social e a instâncias institucionais, recusando assim a divisão texto/ contexto.

\section{ARGUMENTAÇÃO NO DISCURSO VS ARGUMENTAÇÃO NA LÍNGUA}

\section{O lugar da retórica e seus desafios}

É preciso distinguir esta abordagem essencialmente discursiva da "argumentação na língua" iniciada pelos trabalhos de Anscombre \& Ducrot. Foi efetiva e principalmente através deles que os estudos da argumentação penetraram nas ciências da linguagem, nas quais a abordagem pragmático-semântica parece continuar a exercer sua autoridade. Logo, ela define-se contra a abordagem retórica que permanece no centro da argumentação no discurso, de modo que se faz importante insistir, logo de início, nos desafios contemporâneos do debate. De fato, Ducrot, ao denunciar "o otimismo retórico de Aristóteles e de seus inúmeros sucessores” (2004, p. 32), rejeita o logos definido como fala e razão. Ele opõe-se, assim, radicalmente a Perelman \& Obrechts-Tyteca (1958) cuja nova retórica reconhece nos sujeitos falantes a capacidade de discutir problemas comuns e de influenciar-se mutuamente. O que está em pauta para eles é a possibilidade de substituir a violência bruta por uma partilha da

Na tradição da nova retórica de Perelman, não estabeleço uma distinção entre retórica e argumentação (o título de sua obra fundadora de 1958 escrita com L. OlbrechtsTyteca é Traité de l'argumentation. La nouvelle rhétorique). A retórica no sentido aristotélico de arte de persuadir é aqui sinônimo de argumentação. Para uma justificativa mais detalhada dessa escolha cf. Amossy, 2006. 
fala que funda tanto a democracia quanto as relações sociais. Não será tampouco inútil retomar a diferença entre a argumentação retórica e a argumentação linguíística (para utilizar a terminologia de Ducrot): a diferenciação permitirá não somente estabelecer as fronteiras entre as disciplinas no espaço das ciências da linguagem como também colocar em evidência posições divergentes em suas consequiências sociais e políticas.

Na proposta de Anscombre \& Ducrot, a noção de argumentação não é tomada no sentido amplo de arte de persuadir, mas no sentido específico de encadeamento de proposições que conduz a uma conclusão. ${ }^{4}$ Nessa acepção, a argumentação constitui um fato de língua e não de discurso: ela intervém na construção do sentido do enunciado que comporta "como parte integrante, constitutiva, a forma de influência chamada de força argumentativa. Significar, para um enunciado, é orientar" (Anscombre \& Ducrot, 1988, Prefácio). Em outras palavras: "A utilização de um enunciado tem uma finalidade no mínimo tão essencial quanto informar sobre a realização de suas condições de verdade, e essa finalidade é a de orientar o destinatário na direção de certas conclusões, desviando-o das outras" (ibid., p. 113). Assim definida, a argumentação na língua pede por um estudo dos conectores e dos topoï (definidos como os "elementos que garantem encadeamentos discursivos" [Anscombre, 1995, p. 49-50]) por intermédio dos quais opera-se a relação conclusiva entre E1 e E2. Ela acontece mais freqüientemente em séries de enunciados breves construídos ad hoc: cet hôtel est cher, n'y allez pas (esse hotel é caro, não vá lá); il fait chaud, allons nous promener (está calor, vamos dar uma volta) etc.

À primeira vista, compreende-se que Anscombre e Ducrot tenham tido o intuito de integrar, até mesmo nela dissolvê-la, a retórica à linguiística. De fato, eles consideram a retórica como

4 "Um locutor faz uma argumentação quando ele apresenta um e nunciado E1 (ou um conjunto de enunciados) destinado a introduzir um outro (ou um conjunto de outros enunciados) E2" (Anscombre \& Ducrot, 1988, p. 8). 
"extralinguiística" e, como tal, eles se recusam a "confiar-lhe" o estudo das possibilidades de encadeamento argumentativo (ibid., p. 9). Essa exclusão da perspectiva retórica radicalizou-se nos recentes trabalhos de Ducrot, realizados com Marion Carel (2004), nos quais ele traça uma linha divisória bem clara entre o que ele chama de "argumentação retórica" e "argumentação linguiística". Contrariamente às idéias admitidas, esta última não constituiria um meio direto de fazer alguém acreditar em alguma coisa: "os encadeamentos conclusivos do discurso", diz Ducrot, "não constituem, como tais, meios diretos de persuasão, nem mesmo meios parciais" (2004, p. 20). A razão pela qual os encadeamentos argumentativos ligados explícita ou implicitamente por donc (logo, portanto) não concernem ao raciocínio que visa a encadear a aprovação decorre, segundo Ducrot, do fato que em "A donc C" (A logo/portanto C) a conclusão C sempre está incluída em $A$ no nível semântico, portanto puramente linguiístico. Assim, em "Tu conduis trop vite. Tu vas avoir un accident” (Você dirige rápido demais. Você vai sofrer um acidente), a consequiência do excesso de velocidade já está incluída no "trop" (demais, demasiado) de "tu conduis trop vite". O mesmo ocorre em "Pierre a peu travaillé" (Pierre estudou pouco) e "Pierre a un peu travaillé" (Pierre estudou um pouco), que relatam o mesmo tempo indefinido consagrado ao estudo, em que as conclusões "il ne réussira pas à l'examen” (ele não vai passar na prova) ou, ao contrário, "il réussira à l'examen" (ele vai passar na prova) são dadas de antemão no sentido de "peu" (pouco) vs "un peu" (um pouco). Em outras palavras, "Há encadeamentos argumentativos na própria significação das palavras e dos enunciados de que é feito o discurso" (ibid., p. 28). Tudo é interpretado de antemão, na língua, e o raciocínio conclusivo, suscetível de convencer ao fazer partilhar um raciocínio, é apenas uma ilusão/um engodo. Sem entrar aqui antecipadamente nos detalhes de uma posição que manifesta "uma desconfiança radical frente ao discurso" (ibid., p. 32), percebe-se que Ducrot nega a existência no discurso de "uma argumentação racional, que seria capaz de provar, de justificar" (ibid., p. 21). Ele 
desconstrói, dessa maneira, a própria noção de logos, que designa ao mesmo tempo a fala e a razão.

Uma diluição da retórica na argumentação linguiística desse porte acarreta muitas consequiências. Ela propõe efetivamente que as relações humanas regidas pelas trocas verbais escapam da racionalidade, e que a ambição que consiste em gerar um Estado pela interação e pela negociação verbal em favor de uma razão compartilhada é a priori ilusória. À questão de saber por que há argumentação linguiística no discurso de orientação persuasiva, Ducrot responde em termos que rejeitam o logos em proveito do ethos. $\mathrm{O}$ uso dos "donc" contribuiria pura e simplesmente para projetar uma imagem favorável do orador, apresentando-o como um homem aberto ao debate que não impõe de modo rude seu ponto de vista. Consequientemente, o logos aristotélico como forma atenuada da racionalidade que ocupa tradicionalmente o centro do dispositivo retórico aparece como um engodo. "Os encadeamentos argumentativos do tipo donc concernem tanto ao coup de force (imposições pelo poder) quanto às mais rudes afirmações, escreve Ducrot. Sua eficácia persuasiva, que não é, aliás, em nada negligenciável, concerne ao efeito que eles têm sobre o ethos." (ibid., p. 32).

Essa subordinação do logos ao ethos, estreitamente ligada a uma desconfiança radical na força persuasiva do logos, identifica-se por caminhos diferentes com as posições da sociologia dos campos. Curiosamente, o defensor da autonomia do linguiístico concorda aqui com o sociólogo que recusa ao verbal qualquer autonomia: ambos denunciam a fatuidade de uma força argumentativa sustentada pelo logos e suscetível de agir sobre outrem. Em sua discussão com a filosofia da linguagem principalmente representada por Austin, Bourdieu aponta o erro que consiste em buscar a eficácia da fala no próprio discurso. Segundo ele, "a autoridade sobrevém à linguagem de fora" pela razão que esta é necessariamente tomada em trocas simbólicas (e não em simples trocas comunicativas) em que sua força provém de uma adequação entre as propriedades do discurso, do locutor e da instituição que o autoriza a pronunciar o 
discurso. Em suma, o poder da fala provém "das condições institucionais de sua produção e de sua recepção" (Bourdieu, 1982, p. 111). A questão, portanto, no que diz respeito ao impacto de um dado discurso, não é de ver por quais processos linguageiros ele consegue agir sobre o auditório; o que mais importa é saber qual é a situação do orador e a legitimidade institucional conferida à sua fala. Nessa perspectiva, é o ethos que se vê uma vez mais privilegiado à custa do logos. A imagem produzida pelo discurso deve estar em conformidade com aquela que decorre da posição do locutor, e é a posição prévia da qual ele tira a sua legitimidade, e não a força do raciocínio, que confere à linguagem o seu poder.

Disso decorre, portanto, que para Bourdieu, como também para Ducrot, o logos é apenas uma ilusão. Sem dúvida, a crença em sua autonomia, até mesmo em sua existência, cumpre para os dois um papel não neglicenciável: ela permite assegurar o desconhecimento necessário ao bom funcionamento da troca. Mas aqui o essencial é que as condições que tornam possível o poder da fala são puramente institucionais aos olhos do sociólogo, do mesmo modo que são puramente linguiísticas para o semanticista. Elas não se situam no discurso, mas na língua ou na instituição como sistemas. A gestão das relações humanas em favor de um uso racional da linguagem revela-se ilusória tanto num quanto noutro plano teórico.

Uma posição completamente diferente é adotada pela teoria da argumentação no discurso, tal como a expus numa obra publicada com esse mesmo nome (Amossy 2000, 2006). Invocando a retórica no sentido de arte de persuadir tal como ela se desenvolveu de Aristóteles a Perelman, ela concede um lugar central ao logos em sua relação com o ethos e com o pathos. Ela mantém, portanto, no centro do dispositivo comunicacional a força conferida à fala pelo raciocínio e a faculdade de exercer uma influência fazendo com que ele seja compartilhado. Desse modo, ela baseia-se no estudo dos tópicos, dos esquemas argumentativos e dos tipos de argumentos de que o discurso faz uso para justificar um ponto de vista e tornálo aceitável aos olhos do interlocutor. Extraindo a estrutura 
argumentativa do discurso, e os procedimentos aos quais ele recorre, ela pretende mostrar que a força da fala não é puramente intrínseca à língua (na qual as conclusões seriam sempre dadas de antemão), nem puramente exterior à linguagem, porque vinda do poder proveniente da legitimidade institucional. Nesse sentido, o retorno à retórica preconizado por Perelman \& Olbrechts-Tyteca em 1958 não é simplesmente a marca de um otimismo: é uma reivindicação ética que se faz através da reafirmação da função social das trocas verbais como substitutas da violência (de qualquer ordem que seja), e a lembrança da responsabilidade cidadã que, na ausência de qualquer possibilidade de influência mútua pelo logos, revela-se esvaziada de sua substância. O que não implica evidentemente um racionalismo simplista: a argumentação é analisada em situações de discurso variadas em que o logos é objeto de tratamentos complexos. Ela depende das possibilidades da língua e das condições sociais e institucionais que determinam parcialmente o sujeito, fora dos quais a orientação ou a dimensão argumentativa do discurso não pode ser apreendida com discernimento.

\section{A INTEGRAÇÃO DA RETÓRICA À AD}

É preciso insistir aqui sobre dois pontos que caracterizam a argumentação no discurso como um ramo da análise do discurso. Trata-se nesse caso (1) da inscrição da argumentação na materialidade linguageira em que ela participa do funcionamento global do discurso, e (2) da necessidade de examinar os funcionamentos argumentativos no entrecruzamento do linguístico e do social, apreendendo "o discurso como intricação de um texto e de um lugar social" - de maneira que o objeto da $\mathrm{AD}$ "não seja nem a organização textual nem a situação de comunicação, mas aquilo que os une através de um dispositivo de enunciação específico. Esse dispositivo concerne ao mesmo tempo ao verbal e ao institucional" (definição de Maingueneau no Dictionnaire d'AD, especificada em Marges linguistiques, 2005). É o mesmo que dizer que, mesmo afirmando 
sua fidelidade à grande tradição retórica, a argumentação no discurso pretende, entretanto, ancorar o estudo em processos discursivos específicos levando em consideração os avanços das ciências da linguagem. Ao mesmo tempo, ela os associa indissoluvelmente às instâncias socioinstitucionais nas quais se dá a fala. Nesse sentido, são os fundamentos fornecidos pela $\mathrm{AD}$ que permitem conciliar o estudo da argumentação retórica aos funcionamentos discursivos, examinando-os numa situação de discurso, ou seja, numa situação de comunicação preestabelecida, num espaço sociocultural e num campo (no sentido de Bourdieu).

É da natureza comunicacional do discurso que importa partir. Não seria necessário insistir muito nisso: a argumentação retórica, contrariamente à argumentação linguiística de Ducrot, mas também contrariamente a algumas teorias da argumentação fundamentadas no estudo dos raciocínios e dos argumentos tomados a partir de sua própria natureza, deve ser apreendida na perspectiva das trocas verbais. É de Chaim Perelman o mérito de ter colocado em relevo o papel central do público. O orador (que corresponde ao locutor das ciências da linguagem) visa a conseguir a aprovação de um público (ou interlocutor) do qual ele deve levar em conta as premissas; ele deve apostar em seu saber enciclopédico, suas crenças e seus valores compartilhados a fim de transferir às conclusões o acordo concedido às premissas. É, portanto, em função do público que o locutor desenvolve suas estratégias argumentativas. Do público ou pelo menos da imagem que faz dele: o público é sempre, insiste Perelman, uma construção do orador. É a idéia que ele faz de suas premissas, de suas crenças, de suas opiniões que orienta o discurso, seja ele intencional ou não.

Encontram-se aí os postulados de base da linguiística da enunciação para a qual, na qualidade de "linguagem colocada em ação, e necessariamente entre parceiros” (Benveniste, 1966, p. 258), o discurso é, por definição, uma troca. Colocando a noção de "plano figurativo", Benveniste observa que "a enunciação postula um interlocutor”, um "parceiro” com quem o locutor estabelece necessa- 
riamente uma "relação discursiva" (Benveniste, 1974, p. 85). Parece, a partir daí, que é possível ancorar a análise argumentativa numa análise da enunciação preocupada em localizar as marcas linguageiras do locutor e do interlocutor no discurso. Além dos marcadores, tais como os diferentes indícios de alocução - designações nominais, pronomes pessoais -, pode-se encontrar a figura do interlocutor através do conhecimento, das competências, dos valores e das crenças que lhe são atribuídas. Do mesmo modo, o locutor inscreve sua subjetividade em seu discurso através de diferentes marcas, dentre as quais são particularmente significativas as axiológicas e as afetivas (Kerbrat, 1980). Através - mas também além - dessas marcas, a imagem que o locutor constrói em seu discurso pode ser reconstruída combinando as informações fornecidas pelo enunciado e aquela que complementa a enunciação (a entonação, o nível de língua, o estilo etc.). Essa reconstrução do dispositivo de enunciação e do jogo de imagens que aí se estabelece é capital para situar a argumentação no plano discursivo em que ela emerge e no qual ela adquire sentido. Ela permite ver as modalidades segundo as quais a argumentação explícita ou implícita depende ao mesmo tempo do público cuja imagem é projetada no discurso e do locutor cujo ethos se constrói também nas trocas verbais. Seguindo a definição de Aristóteles, reservamos aqui a noção de ethos para a imagem de si mesmo que o locutor constrói em seu discurso.

É preciso, no entanto, considerar que o plano comunicacional assim fixado é inseparável de um dispositivo mais complexo com o qual ele se articula. Trata-se da distribuição dos papéis fornecida pela cena genérica da forma como a define Dominique Maingueneau (1998): cada gênero dispõe de roteiros prévios nos quais o discurso novo se desenrola. Assim, a alocução televisiva presidencial, o debate parlamentar, a reportagem jornalística, o discurso jurídico de defesa, a aula magistral, a carta íntima determinam de antemão, ao menos parcialmente, as regras da troca, as posições que ocupam os parceiros e o tipo de imagem de si mesmo e do outro que podem ser aí legitimadas. Esses gêneros de discurso, dependendo de um espaço 
social e institucional cuja evolução histórica deve ser levada em consideração, inscrevem-se em campos que possuem suas regras próprias, e nos quais o locutor se posiciona em função de sua própria posição e das possibilidades oferecidas pelo estado do campo. Assim, o "je" (eu) marcado no discurso frente a um "vous" (o senhor/a senhora), e que constrói uma imagem de si mesmo em função da representação que faz do outro, está ligado a um papel (o presidente, o repórter, o esposo...) que ele assume de forma diferente em função da posição que ele pode ocupar num campo político, jornalístico, familiar e privado, variável. Ségolène Royal, candidata à presidência da França pelo Partido Socialista francês nas eleições de 2007, ao tomar a palavra diante de seus eleitores para expor seu programa de governo, coloca um "je" de presidenciável cujas possibilidades são moduladas pelo gênero de discurso no qual ela está engajada, o estado do campo político (e principalmente a necessidade de comparar-se com Nicolas Sarkozy, candidato rival de Royal que venceu as eleições de 2007 para presidente pelo partido União para um Movimento Popular, e de se posicionar em seu próprio partido), a posição institucional que lhe confere sua legitimidade, sua qualidade de mulher e o que o gender implica no espaço eleitoral francês etc. É nessa perspectiva que a troca comunicacional assume sua dimensão de troca simbólica, e que o discursivo e com ele o argumentativo mostram-se indissociáveis do socioinstitucional.

No espaço de troca assim concebido manifestam-se as estratégias destinadas a conquistar a convicção, ou mais simplesmente as modalidades da fala que tenta orientar, deliberada ou espontaneamente, maneiras de pensar. Os tratados de argumentação, dentre os quais o de Perelman e de Olbrechts-Tyteca, descrevem os princípios sobre os quais se fundamenta a argumentação. Eles utilizam, assim, os tópicos como argumentos, ou um estoque de lugares-comuns que subentendem o raciocínio, e sobre os quais o locutor pode apoiar-se: por exemplo, o lugar da quantidade, ou do mais se ele fez ou pode fazer o máximo, ele também fez ou pode fazer o mínimo (se ele bateu em seu próprio pai, ele também pode bater 
em seu vizinho). Eles descrevem as grandes categorias de raciocínio que se desenvolvem apoiadas nesses tópicos: o silogismo e o entimema, a analogia, ou propõem como Toulmin (1993 [1958]) um protótipo de esquema argumentativo: dados (D) são antecipados para sustentar uma conclusão $(C)$, passagem que é autorizada por garantias $(\mathrm{G})$ que repousam sobre um fundamento ( $\mathrm{F}$ - backing, B), e ao qual podem ser aplicadas restrições (R). Harry est né aux Bermudes (D) (Harry nasceu nas Bermudas), portanto ele é sujeito britânico $(C)$, dado que aqueles que nascem nas Bermudas são sujeitos britânicos $(G)$ - salvo se seus pais não o fossem (R). Eles estabelecem também uma taxionomia dos diferentes argumentos, tentando extrair tipos de argumentos no seio de categorizações que variam amplamente - ou ainda, como a lógica informal, eles procuram detectar os argumentos falaciosos (os paralogismos).

Entretanto, na perspectiva da argumentação no discurso, é preciso observar que os esquemas assim extraídos e descritos devem ser recolocados não somente num plano comunicacional, mas também na densidade de um discurso situado. Eles constituem formalizações que permitem, certamente, observar como o discurso antecipa um raciocínio que se quer convincente (ou como ele fracassa ao fazê-lo). Eles são, portanto, úteis, até mesmo indispensáveis. Mas tomados em si mesmos, eles são um esqueleto sem carne. Sua reconstrução necessita de fato transformar os enunciados em uma série de proposições lógicas que resumem seus conteúdos apagando tudo o que concerne ao dialógico e tudo o que se elabora na organização textual e na materialidade discursiva (a escolha dos termos, dos conectores, as variações semânticas, o valor do implícito etc.). Para reencontrar o funcionamento argumentativo do discurso, é preciso levar em conta todos esses elementos linguageiros: é preciso observar como os esquemas e os argumentos lógicos ou, segundo a terminologia de Perelman, quase-lógicos (eles não concernem à lógica formal) inscrevem-se no discurso em todos os seus níveis. É preciso assim levar em conta o gênero de discurso com suas regras, sua distribuição prévia de papéis, suas 
restrições frequientemente tácitas, e observar como a troca (real ou virtual) articula-se sobre o socioinstitucional. Pode-se, assim, considerar a argumentação na materialidade linguageira e no espaço social, cultural e institucional, que the conferem sua densidade e sua complexidade.

\section{3. À GUISA DE EXEMPLO: ANÁLISEDEUM EXCERTO DA CORRESPONDÊNCIA DE DREYFUS}

Sem dúvida um exemplo impõe-se neste ponto para concretizar a abordagem acima esboçada rapidamente e justificar a sua pertinência. $O$ excerto abaixo foi retirado da correspondência privada $^{5}$ de Alfred e Lucie Dreyfus, publicada integralmente por V. Duclerc, em 2005, e da qual uma parte (de cuja carta foi tirado o excerto) já havia sido publicada em Lettres d'un innocent (1898):

(...) il s'agit de l'honneur d'un nom, de la vie de nos enfants. Et je ne veux pas, tu m'entends bien, que nos enfants aient jamais à baisser la tête. Il faut que la lumière soit faite pleine et entière sur cette tragique histoire. Rien, par la suite, ne doit ni te rebuter, ni te lasser. Toutes les portes s'ouvrent, tous les cours battent devant une mère qui ne demande que la vérité, pour que ses enfants puissent vivre.

C'est presque de la tombe - ma situation y est comparable, avec la douleur en plus d'avoir un cœur - que je te dis ces paroles.

[...] trata-se da honra de um nome, da vida de nossos filhos. E eu quero, ouça bem o que digo, que nossos filhos nunca tenham que baixar a cabeça. É preciso que a luz seja inteira e plenamente lançada sobre essa trágica história. Nada, na sequiência dos fatos, deve te desencorajar nem desgastar. Todas as portas se abrem, todos os corações batem diante de uma mãe que não quer senão a verdade para que seus filhos possam viver.

É quase da sepultura - minha situação é a isso bem semelhante, com a dor a mais de ter um coração - que eu te escrevo estas palavras.

Sobre a correspondência 
AMOSSY, Ruth. O lugar da argumentação na análise do discurso...

(Alfred Dreyfus a Lucie Dreyfus, Iles du Salut, 15 de julho de 1895, em Alfred et Lucie Dreyfus, 2005, p. 250)

Num primeiro momento, extrairemos os esquemas argumentativos que sustentam e organizam o primeiro parágrafo resumindo-o numa série de proposições. Percebe-se, assim, um raciocínio silogístico que se pode, grosso modo, formalizar da seguinte maneira:

\section{Primeiro silogismo (implícito)}

\begin{tabular}{|c|c|}
\hline Premissa maior (implícita): & $\begin{array}{l}\text { Il faut laisser à ses enfants un nom honorable } \\
\text { (É preciso deixar aos filhos um nome honrado) }\end{array}$ \\
\hline Premissa menor: & $\begin{array}{l}\text { La condamnation pour trahison qui pèse sur Dreyfus } \\
\text { déshonore ses enfants } \\
\text { (A condenação por traição que pesa sobre Dreyfus } \\
\text { desonra seus filhos) } \\
\text { (il s'agit de l'honneur d'un nom (...) que nos enfants aient (...) à } \\
\text { baisser la tête) } \\
\text { (trata-se da honra de um nome (...) que nossos filhos tenham } \\
\text { (...) que baixar a cabeça) }\end{array}$ \\
\hline Conclusão 1: & $\begin{array}{l}\text { Donc il faut faire la lumière sur l'affaire qui entraîne cette } \\
\text { condamnation } \\
\text { (Portanto é preciso lançar a luz sobre o caso que acarreta a } \\
\text { condenação) } \\
\text { (Il faut que la lumière soit faite pleine et entière sur cette tragique } \\
\text { histoire) } \\
\text { (É preciso que a luz seja inteira e plenamente lançada sobre essa } \\
\text { trágica história) }\end{array}$ \\
\hline Conclusão 2: & $\begin{array}{l}\text { Donc Lucie doit tout faire pour rétablir la vérité et rendre ainsi un } \\
\text { nom honorable aux enfants } \\
\text { (Portanto Lucie deve fazer de tudo para restabelecer a verdade e } \\
\text { deixar assim um nome honrado para seus filhos) } \\
\text { (Rien, par suite, ne doit te rebuter ni te lasser) } \\
\text { (Nada, na sequêencia dos fatos, deve te desencorajar nem desgastar) }\end{array}$ \\
\hline
\end{tabular}


Filol. linguiíst. port., n. 9, p. 121-146, 2007.

Segundo silogismo (implícito)

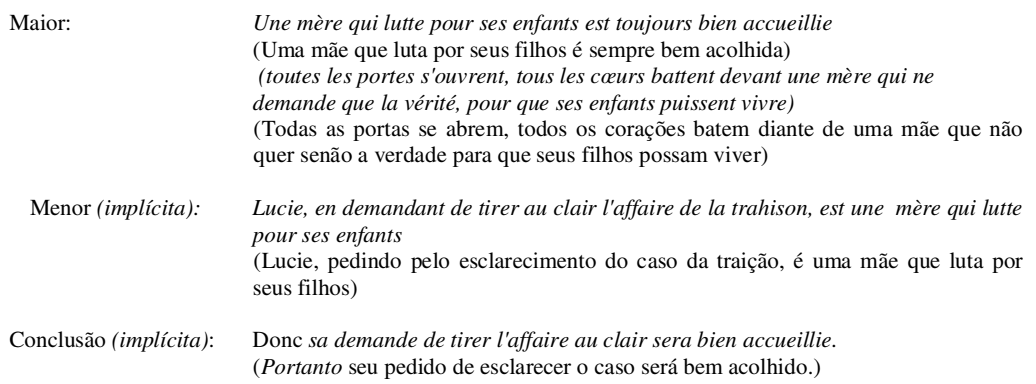

Tal é a estrutura entimemática do discurso (entimema sendo aqui definido como um silogismo implícito: é a forma silogística ordinária no uso corrente). Ela marca um raciocínio que faz com que se passe sem dificuldade das premissas à conclusão e cujo impacto só pode ser grande. O primeiro conjunto é destinado a persuadir Lucie Dreyfus a fazer todo o possível para rever o processo em benefício de seus filhos. Ele repousa sobre uma premissa geral tácita: a honra do nome e a necessidade de transmiti-lo sem manchas às gerações futuras são primordiais. Ela supõe compartilhados valores como a honra e a virtude do patronímico tanto como valores morais quanto como fundamentos da posição social e do bem-estar em sociedade. Todo o peso do argumento repousa nessa premissa maior implícita, ainda mais forte à medida que ela aparece como uma evidência partilhada que não pode ser questionada. A recusa da premissa anularia o conjunto do raciocínio.

O segundo conjunto deve impregnar a destinatária pelo sentimento de que se trata de uma missão realizável. Ele vem varrer uma dúvida inexpressa sobre a eficácia das providências que o missivista pede que sua mulher tome. Como a premissa maior sobre a qual se fundamenta o raciocínio é menos evidente, o locutor toma o cuidado de formulá-la de maneira enfática: "todas as portas se abrem, todos os corações batem diante de uma mãe que...”. 
Aqui, é a menor relativa à situação de Lucie na qualidade de mãe que luta pelo futuro de seus filhos que aparece como um dado de que sua evidência dispensa formulá-la com todas as letras. Do mesmo modo, a conclusão permanece implícita. Isso permite ao locutor não apresentar, preto no branco, uma afirmação cujo otimismo poderia facilmente ser desmentido - a saber, que as providências da esposa de Alfred Dreyfus, condenado como traidor da pátria, serão necessariamente bem acolhidas por todos aqueles aos quais ela se dirigir. É somente graças ao não-dito que a dedução pode aqui obter o seu poder. Omitindo a premissa menor e a conclusão que se referem à situação concreta da destinatária, Alfred contentase em formular na premissa maior um princípio geral, que fundamenta por si só a demonstração. Ele evita, assim, qualquer problematização inoportuna e protege-se das objeções e refutações possíveis.

O surgimento dos esquemas de raciocínio e de seu manejo singular mostra que o logos interpreta um papel não negligenciável no impacto do discurso analisado. Entretanto, fica claro nesse momento que a análise argumentativa fundamentada na reconstrução dos silogismos fornece apenas uma parte do sentido e da força do texto. $O$ projeto de persuasão fundamenta-se também em procedimentos linguageiros que ultrapassam a esquematização esboçada anteriormente e reforçam o impacto da carta.

Será também possível observar na reconstrução dos enunciados a equivalência estabelecida entre a honra do nome e a vida por justaposição: "il s'agit /de l'honneur d'un nom/ de la vie de nos enfants" (trata-se /da honra de um nome/ da vida de nossos filhos). E no final do parágrafo: "une mère qui ne demande que la vérité, pour que ses enfants puissent vivre” (uma mãe que não quer senão a verdade para que seus filhos possam viver). Limpar o nome de Dreyfus da marca que o mancha é permitir que vivam os filhos que o carregam. Disso resulta que o contrário os impediria de viver, seria sinônimo de morte. Observemos que a equivalência estabelecida entre a honra e a vida não é justificada pelo missivista: 
ela impõe-se na variação que justapõe os termos no primeiro caso e na relação forte da verdade com a possibilidade de vida no segundo caso. Remetendo aos valores sobre os quais repousa a totalidade do raciocínio, o discurso epistolar nele os inscreve a título de evidência em suas escolhas semânticas e em suas construções sintáticas. O problema que incumbe a Lucie resolver é em seguida apresentado como crucial: sua missão refere-se a uma questão de vida ou de morte cuja urgência não pode ser discutida.

Antes de prosseguir na análise dos processos discursivos que constroem a demonstração, é importante lembrar o dispositivo e a situação de enunciação na qual se desenvolve a argumentação e na qual ela adquire seu pleno alcance. De fato, os esquemas argumentativos colocados em relevo inscrevem-se no gênero da carta íntima em que a troca, que se supõe sincera e espontânea, permite a expressão dos sentimentos profundos, dos projetos e dos desejos mais pessoais, e não pede por demonstrações formais rigorosas. No caso em questão, trata-se - à margem do caso Dreyfus tal como se desenrola em praça pública - de uma correspondência privada entre um marido e sua esposa, dos quais o primeiro, o capitão Dreyfus, é detido por traição em condições particularmente severas nas Ilhas da Salvação, e mais precisamente a partir de 13 de abril na Ilha do Diabo. A troca de correspondência privada, iniciada em 4 de dezembro de 1894, foi submetida a uma censura das mais rigorosas, e continuou na época do excerto aqui estudado, 15 de julho de 1895, depois de mais de 7 meses, de maneira irregular: Dreyfus recebeu somente em 12 de junho de 1895 as primeiras notícias de sua mulher desde sua partida para a Guiana em 21 de fevereiro, depois em 29 de junho de 1895 notícias relativamente recentes. Foi nessas condições bastante estritas de isolamento que o missivista, aniquilado por uma condenação da qual ele não compreendia nem as causas nem as consequiências e a qual ele considera como um trágico erro, dirigiu-se à sua esposa Lucie.

As cartas precedentes já expressavam a indignação do capitão, de quem haviam tirado não somente a liberdade, mas também 
a honra, e narravam o sofrimento moral e físico que ele sofrera - o que ambos, marido e esposa, chamavam de seu "martírio". É, portanto, no conjunto de uma correspondência caracterizada pela retomada e por uma repetição quase lancinante que se insere a passagem anteriormente transcrita. Esta participa, da parte de Alfred, de um projeto global: apoiar Lucie e levá-la a fazer tudo o que for possível, já que ele próprio encontra-se na impossibilidade de intervir, para obter a revisão de seu processo e a anulação de uma condenação errônea e injusta. É preciso, portanto, notar que a missiva dirige-se a uma destinatária doravante devotada à causa que compartilha os valores e as convicções de seu marido e está pronta para fazer o que for possível para ajudá-lo. Além disso, os argumentos familiares que Dreyfus faz valer são os mesmos que Lucie havia utilizado para persuadi-lo a continuar a viver na provação terrível que enfrentava: 26 de dezembro de 1894: "Je te demande un énorme sacrifice, celui de vivre pour moi, pour tes enfants, de lutter jusqu'à ta réhabilitation..." (Peço-te um enorme sacrifício, o de viveres para mim, para teus filhos, de lutares até a tua reabilitação) (ibid., p. 88); 4 de janeiro de 1894: "Tu m'as promis de lutter jusqu'au bout pour moi, pour les enfants, je t'en ai une immense reconnaissance" (Tu me prometeste que lutarias até o fim por mim, pelas crianças, sou-te eternamente grata) (ibid., p. 112). A argumentação desenvolvida pelo discurso epistolar aparece consequientemente como a retomada e a modulação de um já-dito, de uma troca em que os mesmos argumentos circulam entre ambos. Para Alfred, trata-se menos de persuadir aquela que pensa como ele que sustentar a cada dia sua luta para fazer com que a verdade seja reconhecida e, sobretudo, de marcar a sua importância crucial e a sua urgência apesar dos obstáculos que podem desencorajar a melhor das boas vontades. A carta deixa de fato entrever as dificuldades que ela pode encontrar: "rebuter" (desencorajar) refere-se às afrontas que será preciso sofrer para se fazer ouvir, "lasser" (desgastar) marca a necessidade de repetir incessantemente as mesmas providências. Não somente essas dificuldades não são formuladas dire- 
tamente como também são apresentadas sob forma negativa e energicamente apagadas pelo "rien" (nada): "Rien, par suite, ne doit te rebuter ni te lasser" (Nada, na sequiência dos fatos, deve te desencorajar nem desgastar). É com essa forma assertiva, até mesmo imperativa, que o locutor tira a conclusão do raciocínio (Portanto Lucie deve fazer de tudo para restabelecer a verdade e dar assim um nome honrado aos filhos) dirigido à destinatária. O caráter condensado da formulação, seu caráter elíptico, seu ritmo contribuem para a força da solicitação.

Compreende-se desde então o caráter enfático de toda a injunção e o caráter insistente do discurso. A vontade de Alfred, que se manifesta no "Je ne veux pas, tu m'entends bien" (eu não quero, ouça bem o que eu digo), coloca o locutor na posição daquele que tem o direito de fazer prevalecer junto à sua destinatária o seu ponto de vista, até mesmo de fazer ouvir suas exigências. Mas ele não fala somente na qualidade de esposo e de senhor que orienta sua mulher que ficou sozinha no lar. Ele faz também ouvir a voz do pai que se revolta com a idéia do mal feito a seus filhos. O nos enfants (nossos filhos) associa a destinatária a esse sobressalto de dignidade ferida e a essa inquietude de pai. Do mesmo modo, a objurgação de "il faut que la lumière soit faite" (é preciso que a luz seja lançada), "rien ne doit ni ... ni” (nada deve nem ... nem), é tanto uma solicitação quanto uma ordem. Dirigido a uma companheira amante, a mistura da injunção sustentada por uma forte vontade com a solicitação insistente de um homem reduzido à impotência confere ao discurso uma força persuasiva que aumenta a do raciocínio. $O$ pathos - a solicitação de aderir às suas inquietudes sobre o destino dos filhos, o tormento e a revolta que trai a veemência da entonação, o desespero de um homem reduzido à impotência - junta-se ao caráter restritivo dos esquemas lógico-discursivos que sustentam o discurso e o fundamentam com a razão. $O$ discurso cria assim o difícil equilíbrio entre o logos (o raciocínio lógico) e o pathos (a afetividade) de que se nutrem a cor- 
respondência íntima e a solicitação que ela lança na direção da parceira.

Além da aliança do logos e do pathos, a carta elabora um jogo de imagens de si e do outro que devem contribuir para com o projeto de persuasão. De sua destinatária, o missivista projeta a imagem de uma mãe devotada e corajosa pronta para fazer o que for possível para a salvação de seus filhos. Ele apresenta-lhe assim o espelho no qual ela pode contemplar o reflexo ideal ao qual ela deve igualar-se. A emulação deve ser ainda mais forte pelo fato de $o$ modelo ser mais pregnante: a maternidade pronta para todos os sacrifícios é um paradigma potente naquele fim de século. Ao mesmo tempo, Dreyfus esboça a imagem de uma mulher ativa na inversão dos papéis que impõe a situação e a que faz alusão o parágrafo precedente: "Si donc [mon énergie] est toute passive, ton énergie au contraire doit être tout active et animée du souffle ardent qui alimente la mienne" (Portanto, se [minha energia] é totalmente passiva, tua energia, ao contrário, deve ser totalmente ativa e reanimada pelo sopro ardente que alimenta a minha) (ibid., p. 250). Alfred pede à sua mulher burguesa, confinada à esfera do privado, para agir no espaço público e para interpretar aí um papel ativo; ela deve, por sua iniciativa e sua atividade, cumprir a tarefa essencialmente confiada ao homem da família, o irmão de Alfred Mathieu Dreyfus. Ao mesmo tempo, ele também toma o cuidado de justificar racionalmente a necessidade para sua mulher de preencher essa função para ela inusitada e de projetar uma imagem segura e gratificante pelo viés do estereótipo da maternidade pronta para enfrentar todas as provações. A construção de uma imagem da destinatária, que participa do projeto de persuasão, é reveladora das representações dominantes da mulher e da relação entre os sexos naquela época. Ele mostra consequientemente a maneira pela qual é dada ao discurso epistolar a função de adaptá-las ao seu próprio objetivo.

Quanto ao missivista, ele projeta uma imagem de homem que continua a guiar a razão e a paixão pela verdade. Nessa ordem de idéias, o vocabulário selecionado coloca Dreyfus do lado dos cida- 
dãos esclarecidos. Ele não pede simplesmente que justiça lhe seja feita, mas "Que la lumière soit faite pleine et entière" (Que a luz seja inteira e plenamente lançada) sobre um mistério judiciário que remonta ao erro ou à maquinação (somente pouco a pouco a tese do erro se transformará na da maquinação). Dreyfus sustenta as luzes da razão e da verdade contra o obscurantismo e a mentira, e a escolha de uma expressão fixa (faire la lumière sur - lançar luz sobre ) não concerne apenas ao clichê de estilo, ela também evoca a ideologia das Luzes e o campo republicano do qual faz parte o capitão, fiel servidor da Terceira República Francesa. Destaca-se, aliás, em sua carta o fato de que a "luz" colocará necessariamente em evidência sua inocência ultrajada, a qual o condenado reafirma implicitamente ao solicitar que se lance uma luz plena sobre sua "trágica história”, dando, por esse desejo de transparência, uma prova de sua inocência ainda mais eloquiente que qualquer afirmação explícita. Dreyfus apresenta-se ao mesmo tempo como inocente, como homem corajoso que pretende continuar na luta e como pai de família que vela pelo futuro de seus filhos.

Contribui com esse ethos o caráter testamentário que Alfred dá à sua carta, e que lhe dá mais peso ainda por manifestar de alguma forma suas últimas vontades: "C'est presque de la tombe - ma situation y est comparable, avec la douleur en plus d'avoir un cœur - que je te dis ces paroles" (É quase da sepultura - minha situação é a isso bem semelhante, com a dor a mais de ter um coração - que eu te escrevo estas palavras) (ibid., p. 250). Essa postura é justificada pelas condições de vida do locutor - o isolamento completo num espaço deliberadamente restrito ao máximo, numa ilha longínqua. Ela contrasta curiosamente com a forte vontade e a injunção insistente expressas no parágrafo precedente, sobrepondo à voz do combatente pela verdade aquela do homem esfacelado mais próximo da morte que da vida (mesmo que Alfred tivesse aceitado não atentar contra sua própria vida por sua família, à qual ele deve o estabelecimento da verdade). O missivista projeta, assim, um ethos complexo feito de oposições: pater familias e mártir impotente, lu- 
tador e ser esfacelado, revoltado que incita à ação e homem invadido pelo frio da morte, que contribui com a força de sua palavra. De fato, ele se mostra digno de ser ouvido e seguido por sua coragem na adversidade, digno também de ser defendido em razão da imensa compaixão que suscita seu martírio. O discurso epistolar constrói, assim, na direção de Lucie, um ethos que deve contribuir para com a força do logos - mas não, certamente, substituí-lo erradicando-o.

É interessante perceber como a mesma passagem recebe uma orientação argumentativa diferente num plano que não é mais aquele da troca epistolar privada. De fato, uma parte das cartas, das quais a de 15 de julho de 1895, foi objeto de uma publicação em 1898 pela iniciativa de Joseph Reinach enquanto Dreyfus estava preso na Ilha do Diabo sem nenhuma informação da luta realizada a seu favor. O livro foi publicado com o título de Les lettres d'un innocent. Fora do formato e do ambiente da troca íntima entre o casal e sob os olhos do grande público, presumir-se-ia que a correspondência testemunharia pela inocência do condenado. $\mathrm{O}$ modo de publicação modificou de fato a orientação argumentativa. O formato da carta privada, espontânea e sem artifícios, funciona aqui como a garantia da autenticidade dos sentimentos de Dreyfus. Ele desvenda a mistura de abatimento e de revolta que ele experimenta em face de uma acusação da qual ele não compreende manifestamente o mistério. Reinach, que escreve a introdução, deixa a apresentação das provas judiciárias o resolva. Oferecendo a leitura da correspondência ao público, ele quer simplesmente fazer a voz de Dreyfus ser ouvida: é a imagem de si mesmo construída pelo missivista num discurso privado que não é em sua origem destinado a terceiros que deve conquistar a convicção do leitor, fora de toda prova material. Nesse plano de comunicação, a carta confiada ao espaço público segue uma orientação argumentativa que não estava programada no início pelo missivista. O projeto de persuasão desenvolvido para Lucie, desviado de seu curso, perde sua pertinência. Ele torna-se uma encenação destinada a terceiros a fim de contribuir com a edificação do ethos em que se sustenta a inocência do capitão. 
É, portanto, uma argumentação completamente diferente que se produz a partir do momento em que o mesmo texto é integrado num outro plano genérico (da carta privada à carta pública, porque publicada), dirigido a um público diferente (o leitor francês de 1898 e não Lucie), por um emissor diferente (Reinach e o editor por detrás de Dreyfus, ainda na Ilha do Diabo, onde ele não pode saber dessa publicação), em circunstâncias diferentes (a participação de uma violenta polêmica em torno do caso em 1898, e não de uma troca privada). Poder-se-ia desse ponto de vista retomar toda a análise e mostrar como a argumentação da passagem estudada recompõe-se e reconstrói-se no espaço das Lettres d'un innocent (Amossy, no prelo). Esse caso mostra claramente que a argumentação tal como ela se inscreve num texto concreto muda numa situação de discurso diferente mesmo que nenhum termo da missiva tenha sido modificado. O funcionamento discursivo da argumentação depende, como dissemos anteriormente, do plano da troca verbal (que é também uma troca simbólica) no qual ela emerge e se desenvolve.

\section{CONCLUSÃO}

\section{A argumentação no discurso como ramo da AD}

Percebe-se, a partir dessa breve exemplificação, como a análise da argumentação é indissociável daquela do funcionamento de um discurso em situação. Percebe-se também como o estudo da eficácia da fala passa necessariamente pela do logos em sua relação constitutiva com relação ao ethos e ao pathos. Nem os princípios semânticos de encadeamento dos enunciados, nem as regras institucionais que conferem à fala legitimidade e poder são suficientes para dar conta da maneira pela qual a troca verbal tenta influenciar modos de ver e de pensar. A eficácia da fala deriva das modalidades segundo as quais os esquemas constitutivos do logos inscrevem-se na materialidade linguageira, no seio de um dispositivo de enunci- 
ação dependente de uma situação de discurso que compreende componentes socioculturais e institucionais.

Nesse sentido, a argumentação participa do funcionamento do discurso que a $\mathrm{AD}$ explora. É consequientemente uma articulação totalmente particular da retórica e das ciências da linguagem que se propõe aqui. Sem dúvida, a relação da antiga retórica com a pragmática e com a $A D$ é freqüientemente evocada: Teun van Dijk propõe essa relação ao atribuir as origens do "discourse analysis" à retórica clássica (1985, p. 1). Em termos de genealogia, entretanto, é preciso considerar o fato de que as formas tomadas pela retórica são "dependentes de configurações do saber e de práticas irremediavelmente desaparecidas" (Maingueneau, 2005, p. 65): segundo Maingueneau, "a análise do discurso implica uma "ordem do discurso" irredutível ao dispositivo retórico" (ibid.). No entanto, mais que ater-se a uma divisão inevitável entre disciplinas nascidas em períodos históricos diferentes, parece-me produtivo redefinir a análise da argumentação à luz das ciências da linguagem contemporâneas. Por esse viés, trata-se de integrá-la plenamente ao âmbito da $A D$, entrevendo nas modalidades verbais da persuasão um aspecto inerente ao discurso tomado na variedade de seus dispositivos. Parece-me que (para retomar à minha maneira um exemplo de D. Maingueneau que trata da divisão entre as tarefas das disciplinas), ao analisar um debate político na televisão, o fato de considerar o público, a natureza e os modos de encadeamento dos argumentos, do ethos etc. não concerne a um procedimento diferenciado, mas, ao contrário, ele se integra ao trabalho da $\mathrm{AD}$ que se interroga "sobre o próprio gênero de discurso, sobre a composição textual, sobre os papéis sociodiscursivos que ele implica, sobre a definição do político que implica esse gênero televisual etc." (Maingueneau, 2005, p. 67). É nesse sentido que a argumentação no discurso mostra-se indissociável da $\mathrm{AD}$. 
Filol. linguiíst. port., n. 9, p. 121-146, 2007.

\section{BIBLIOGRAFIA}

AMOSSY, R. (2006 [2000]) L'argumentation dans le discours. Paris: Colin.

. (2005) The argumentative dimension of discourse In: EEMEREN, F. H. van; HOUTLOSSER, P. (eds.). Practices of argumentation. Amsterdam: John Benjamins Publishing Company, p. 87-98.

ANSCOMBRE, J-Cl.; DUCROT, O. (1988) L'Argumentation dans la langue. Liège: Mardaga. ARISTOTE. (1991) Rhétorique. Trad. Ruelle, introd. M. Meyer, commentaire de B. Tmmermans. Paris: Le livre de poche.

BENVENISTE, E. (1974) Problèmes de linguistique générale, 2. Paris: Gallimard. . (1966) Problèmes de linguistique générale, 1. Paris: Gallimard.

BOURDIEU, P. (1982) Ce que parler veut dire. Léconomie des échanges linguistiques. Paris: Fayard.

CHARAUDEAU, P. (2005) Le discours politique. Les masques du pouvoir. Paris:Vuibert.

CHARAUDEAU, P.; MAINGUENEAU, D. (éds). (2002) Dictionnaire d'analyse du discours. Paris: Le Seuil.

DUCROT, O. (2004) Argumentation rhétorique et argumentation linguistique. In: L'argumentation aujourd'hui. Positions théoriques en confrontation. Paris: Presses de la Sorbonne Nouvelle.

DREYFUS, A. (1898) Lettres d'un innocent. Paris: Stock.

DREYFUS, A.; DREYFUS, L. (2005) Ecris-moi souvent, écris-moi longuement. Correspondance de l'Ile du Diable. Édition établie par Vincent Duclerc, Avant-propos de Michèle Perrot. Paris: Mille et une nuit.

KERBRAT-ORECCHIONI, C. (1990) Les interactions verbales, t. I. Paris: Colin. . (1980) L'Énonciation de la subjectivité dans le langage. Paris: Colin.

MAINGUENEAU, D. (2007 [1998]) Analyser les textes de communication. Paris: Colin. . (2005). L'analyse du discours et ses frontières. Marges linguistiques, 9, Mai. 2005, M.L.M.S éditeur http://www. Marges-linguistiques.com

PERELMAN, Ch.; OLBRECHTS, T. O. (1958) Traité de l'argumentation. La nouvelle rhétorique. Bruxelles: Éditions de l'Université de Bruxelles.

SIESS, J. (éd.) (1998) La lettre entre réel et fiction. Paris: SEDES.

TOULMIN, S.E. (1993 [1958]) Les usages de l'argumentation. Paris: Presses Universitaires de France.

VAN DIJK, T. (1985) Discourse Analysis as a new cross-discipline. In: VAN DIJK, T. (ed.) Handbook of Discourse Analysis, v. 1. New York: Academic Press. 
AMOSSY, Ruth. O lugar da argumentação na análise do discurso...

RÉSUMÉ: Qu'il y ait visée ou simplement dimension argumentative, l'argumentation fait toujours partie intégrante du discours en situation. Elle doit de ce fait être prise en compte par l'AD, à qui il revient d'explorer son inscription dans la matérialité langagière, mais aussi son ancrage social et institutionnel. L'approche ici proposée est exemplifiée dans l'analyse d'une lettre d'Alfred Dreyfus. Se ressourçant dans la rhétorique antique qu'elle soumet aux avancées des sciences du langage, l'argumentation dans le discours s'oppose à l'argumentation dans la langue qui nie les vertus du logos. Face aux positions qui dénient à celui-ci tout pouvoir, il importe de mettre en avant un partage de la parole qui est au fondement des relations humaines comme de la responsabilité citoyenne.

MOTS-CLÉS: Analyse du discours; argumentation; visée et dimension argumentatives; argumentation linguistique 